\title{
Applying Dickson Quality Index, Chlorophyll Fluorescence, and Leaf Area Index for Assessing Plant Quality of Pentas lanceolata
}

\author{
Kuan-Hung LIN ${ }^{1,2}$, Chun-Wei WU ${ }^{3 *}$, Yu-Sen CHANG ${ }^{4 * *}$ \\ ${ }^{1}$ Ton Duc Thang University, Faculty of Applied Sciences, Ho Chi Minh City 700000,Vietnam; linkuanhung@tdtu.edu.vn; \\ ${ }^{2}$ Chinese Culture University, Department of Horticulture and Biotechnology, Taipei 114, Taiwan; rlin@faculty.pccu.edu.tw \\ ${ }^{3}$ Kang Ning University, Center for General Education, Taipei 114, Taiwan; r88628115@gmail.com ('co-corresponding author) \\ ${ }^{4}$ National Taiwan University, Department of Horticulture and Landscape Architecture, Taipei 106, \\ Taiwan; yschang@ntu.edu.tw ( ${ }^{* *}$ correspondingauthor)
}

\begin{abstract}
Plant quality greatly relates to the seedling vigor (SV), survival and growth of plants after transplantation. The objective of this study was to use the nondestructive measurements of chlorophyll fluorescence (ChlF) and leaf area index (LAI) as SV indices for star cluster (Pentas lanceolata). Plants were grown in potting soil under nature sunlight for $90 \mathrm{~d}$. A total of 13 morphological and physiological parameters were selected for measurements. Among them, root growth potential (RGP) was the best predictor for SV in all tested plants. Plants were separated into 5 RGP groups based on the number of new roots, and remaining parameters were also separated into those same levels. The trends and rates of increase from levels 1 to 5 in Dickson quality index (DQI), LAI, total dry mass, and ChlF were all similar to the RGP index. Although RGP and DQI are frequently used as indices for $\mathrm{SV}$, these measurements are time-consuming and require sample destruction. Consistent and strongly high correlations were observed among DQI, LAI, and ChlF, demonstrating the applicability of these indices for measuring SV in star cluster. The measurements of LAI and ChlF were predicted using multiple variables from validation datasets, and showed novel and useful parameters for examining the SV of star cluster.
\end{abstract}

Keywords: nondestructive; photosynthesis; reflectance spectroscopy; root growth potential; seedling vigor

Abbreviations: ChlF, chlorophyll fluorescence; DQI, Dickson quality index; Fv'/Fm', maximum quantum yield; LAI, leaf area index; NDVI, normalized difference vegetation index; NPQ, nonphotochemical quenching coefficient; RGP, root growth potential; $S Q$, sturdiness quotient; $S V$, seedling vigor.

\section{Introduction}

Plant quality influences the seedling vigor (SV), growth and survival of nursery plants after transplanting, and is greatly influenced by cultivation techniques and environmental conditions (Mattsson, 1997). High SV plants are healthy, exhibit strong growth and vitality, have dominant stems, occupy large root zones, have balanced shoot/root $(S: R)$ ratio, and are tolerant of moderate drought and high levels of irradiation (Wightman, 1999). Assessing SV at the juvenile stage serves as an index for survival and growth of field plants. Additionally, the initial assessment of seedling morphology parameters mostly focus on plant height, root length, root growth potential (RGP), dry mass, root collar, $S: R$ ratio, and sturdiness quotient $(S Q$, plant height/root collar diameter) (Radolou and Raftoyannis, 2002). Physiological indices such as photosynthetic performance, spectral reflectance, water potential, electrical conductivity of cell tissues, mineral or carbohydrate content, and chlorophyll content also greatly influence seedling survival. Unfortunately, most of these assessment methods are single indicators that may not be sufficiently representative of SV. Dickson quality index (DQI) was originally designed for assessing the quality of Norway spruce (Picea abies) and eastern white pine (Pinus strobes) seedlings, and is a product of total dry mass divided by the sum of S:R and SQ (Dickson et al., 1960). Conventionally, SV has been measured by visual observation or destructive testing. Visual observations frequently cause experimental errors, whereas destructive measurements damage plants and make further experiments impossible. Previously, DQI, RGP, seedling height, and photosynthetic performance often have been used as 
170

indicators for SV, but are time-consuming and destructive to plants (Ellison et al., 2016).

Under natural conditions, photosynthesis is regulated biochemically in response to environmental changes to maintain a balance between the rates of component processes and concentrations of metabolites. Plants adapt photosynthesis to a certain degree in response to the prevailing environment, and the sensitivity of photosynthesis to stress varies among plant species and cultivars. Photoinhibition of photosynthesis is characterized by a reduction in the quantum yield of photochemistry and a decrease in chlorophyll fluorescence (ChlF), which entails not only the inhibition of photosystem (PS) II but also increases thermal de-excitation of excited chlorophyll (Chl) (Demming-Adams et al., 1996). The ChlF measurement, a noninvasive technique, has been widely used in a range of photosynthetic organisms and tissues to study the functional changes in the photosynthetic apparatus in controlled environments and in the field under varying stress intensities (Huang et al., 2013; Wilson and Jacob, 2012). Using the ChlF imaging system, Chiu et al. (2015) found that leaf spots on cabbage seedlings could be detected 8 h earlier compared with using a charge-coupled device camera. Recently, Kowalczyk et al. (2018) assessed the quality and storage ability of the lettuce and to determine ChlF parameters, which could well characterize early changes of quality during plant growth, production, and storage. Reflectance spectroscopy is another under-exploited noninvasive technique that can be used in physiological studies because of its simplicity, rapidity, and nondestructive nature (Levizou et al., 2005). Various reflectance spectra from leaves have been employed to calculate a series of vegetation indices used to monitor plant growth. Reflectance spectra are altered when stress occurs, enabling the use of a series of different vegetation indices such as the normalized difference vegetation index (NDVI) for a quantitative yield measurement of plant growth (Devitt et al., 2005). Different theoretical models based on leaf reflectance exist to predict leaf $\mathrm{Chl}$ content, water content, and other variables associated with vegetative structure (Strachan et al., 2002). Previously, we found that validation of leaf soil-plant analysis development (SPAD), NDVI, and $\triangle F / F m$ ' indices are accurate predictors of leaf nitrogen $(N)$ concentration and can be used for non-destructive estimation of the proper timing for $\mathrm{N}$-solution irrigation of P. lanceolata (Wu et al., 2015). Therefore, reflectance indices may be useful for measuring leaf SV in bedded ornamental plants grown in an open field.

The objectives of this study were to employ nondestructive measurements to determine SV and develop a precise, integrated, and quantitative measurement of star cluster. We attempted to determine whether ChlF and LAI could be used as sensitive metrics to develop algorithms for estimating plant SV corresponding to DQI. Experimental plants were examined morphologically and physiologically to establish SV indices. Rapid and nondestructive measurements of leaf area index (LAI) and ChlF were used to assess plant status to accelerate the analysis of plant SV. $\mathrm{LAI} \times(\Delta \mathrm{F} / \mathrm{Fm})$ represents novel and useful parameters for examining the SV of star cluster and provides insight into the evaluation of plant SV.

\section{Materials and Methods}

\section{Experimental site and plant material}

Star cluster (Pentas lanceolata) belong to tropical plant and is one of the few ornamental plants that grow well under high temperature and humidity of Taiwan summers, and is commonly used in flower beds. Seeds of star cluster were purchased from Known-You Seed Co. (Taipei, Taiwan) for our experiments. Seeds were germinated and grown on plastic plug trays (Blackmore Inc., CA, USA) with 288 cells tray $\left(6.18 \mathrm{~cm}^{3}\right.$ cell $\left.^{-1}\right)$ for 2 weeks until the seedlings were about 3 to $6 \mathrm{~cm}$ in height. The medium used was a commercial potting mix of peat moss and perlite (4:1 $\mathrm{v} / \mathrm{v})$. The seedlings were then transplanted into 5 -inch pots $(1939 \mathrm{~mL})$, and grown in an open field at National Taiwan University from late July to early September 2014 (1500 $\mu \mathrm{mol} \cdot \mathrm{m}^{-2} \cdot \mathrm{s}^{-1}$ photosynthetic photon flux $(P P F)$. Average day/night temperatures and day length were $31.4 / 27.9^{\circ} \mathrm{C}$ day/night and $14 \mathrm{~h}$, respectively, during the period of study. Plants were watered three times a week, and an optimal amount of a compound fertilizer solution $\left(\mathrm{N}-\mathrm{P}_{2} \mathrm{O}_{5}-\mathrm{K}_{2} \mathrm{O}\right.$, 20-20-20, Peters Professional, OH, USA) was applied once a week. Plants ranging in size from 28 to $60 \mathrm{~cm}$ in height were used for SV testing of DQI, LAI, RGP, total dry mass, $S: R$ ratio, sturdiness quotient, ChlF, and spectral reflectance. Twenty samples were randomly selected and grouped into 5 classes according to RGP. Various quality associated parameters were evaluated against DQI for the selection of a non-destructive index to replace DQI.

\section{Seven phenotypic traits were measured in each plant:}

1. Plant height, measured as the height $(\mathrm{cm})$ above the soil;

2. Root collar diameter $(\mathrm{mm})$, measured at $1 \mathrm{~cm}$ under the soil surface using a Vernier caliper;

3. Sturdiness quotient (SQ), calculated by dividing plant height by root collar diameter;

4. Shoot/root $(S: R)$ ratio, measured as shoot dry mass divided by root dry mass;

5. Dickson quality index (DQI), measured as plant total dry mass (numerator) divided by summation of $S Q$ and $S: R$ ratio (denominator). Samples were dried in an oven at $70^{\circ} \mathrm{C}$ for four days and measured as dry mass;

6. Root growth potential (RGP). At $90 \mathrm{~d}$, roots were carefully removed from each plant's attached soil medium without damaging them. Roots were cleaned with water to remove excess soil and trimmed, followed by re-planting into soilless media consisting of peat moss and perlite in a ratio of $4: 1(\mathrm{v} / \mathrm{v})$. Plants were then given optimal water and fertilization. After four weeks, plants were lifted out of the growth media and the number of newly grown roots $>1 \mathrm{~cm}$ in diameter were counted (Tanaka et al., 1997); and

7. Leaf area index (LAI), as measured by a portable LAI2000 Plant Canopy Analyzer (LI-COR; Lincoln, Nebraska, USA) and calculated by dividing all leaf area $\left(\mathrm{m}^{2}\right)$ by canopy structure $\left(\mathrm{m}^{2}\right)$, was compared to radiation measurements (Facchi et al., 2010).

Among morphological and physiological parameters, the trends and rates of increases from level 1 to 5 in DQI, LAI, total dry mass, $\triangle \mathrm{F} / \mathrm{Fm}$ ', and $\mathrm{qP}$ were recorded. 
Chlorophyll fluorescence (ChlF)

Chlorophyll fluorescence (ChlF) parameters were measured at ambient temperature in dark-adapted for 30 min with a portable modulated fluorometer (MonitoringPam Multi-Channel Chl Fluorometer; Heinz Walz $\mathrm{GmbH}$, Inc., Effeltrich, Germany). Tested plants at the middle portion of mature, healthy, and fully expanded third leaves were targeted for measurements. The minimal chlorophyll fluorescence (Fo) and maximal chlorophyll fluorescence $(\mathrm{Fm})$ of dark-adapted samples were determined with modulated irradiation of a weak blue light emitting diode (LED) beam (measuring light) and saturating pulse, respectively. The maximum photochemical quantum yield $(\mathrm{Fv} / \mathrm{Fm})$ was then calculated where $\mathrm{Fv}$ was the yield of variable fluorescence calculated as Fm-Fo. For measurements of $\mathrm{Fv} / \mathrm{Fm}$, samples were well-acclimated to dark conditions so that all reactions centers were in the open state and non-photochemical dissipation of excitation energy was minimal. The sample was continuously irradiated with actinic light for $6 \mathrm{~min}$. The intensity of actinic light $1500 \mu \mathrm{mol} \cdot \mathrm{m}^{-2} \cdot \mathrm{s}^{-1}$ was selected which was equivalent to the actual growth light. During the lightadapted state, the $\mathrm{F}$ ' was detected shortly before a saturating pulse applied. A saturating pulse at $4,000 \mu \mathrm{mol} \cdot \mathrm{m}^{-2} \cdot \mathrm{s}^{-1}$ was subsequently imposed to determine the maximum chlorophyll fluorescence level in the light (Fm'). The effective photochemical quantum yield of PSII $(\Delta \mathrm{F} / \mathrm{Fm}$ ') in the light-adapted state is given as $\Delta \mathrm{F} / \mathrm{Fm}^{\prime}=\left(\mathrm{Fm}^{\prime}-\mathrm{F}^{\prime}\right) / \mathrm{Fm}^{\prime}$, where $\Delta \mathrm{F}$ is the variation of chlorophyll fluorescence levels between Fm' and F'. The quantum yield of electron transfer at PSII (ФPSII) is a measurement of the overall efficiency of the PSII reaction centers. Several parameters can then be computed based on modulated fluorescence kinetics: NPQ $($ non photochemical quenching $)=\left(\mathrm{Fm}-\mathrm{Fm}^{\prime}\right) / \mathrm{Fm}^{\prime} ; \mathrm{qP}=$ $\left(F^{\prime}-F^{\prime}\right)$ / (Fm'-Fo'), where Fo' is the minimal fluorescence level of an illuminated sample that is lowered than Fo. The Fo' level was determined during a dark interval following the saturating pulse (Kitao et al., 2006; Porcar-Castell et al,. 2008). Measurements were recorded by the WinControl-3 software (Heinz Walz, Effeltrich, Germany).

\section{Reflectance spectroscopy}

Spectral reflectance was measured from mature, healthy, fully expanded third leaves at wavelengths of 305-2150 nm at $1 \mathrm{~nm}$ intervals using a Handy Spec Field 2.2 Tec5 spectrophotometer (Oberursel, Germany). Various spectra were used to calculate the vegetation index and determine any useful information related to SV, such as normalized difference vegetation index (NDVI), which is calculated as (R800 - R660) / (R800 + R660) (Devitt et al., 2005).

\section{Statistical analysis}

SV measurements were analyzed by a completely randomized analysis of variance (ANOVA) that compared the different levels of SV for each parameter. For significant values, means were separated by Fisher's least significant difference (LSD) test at $p<0.05$ using CoStat ver. 6.4 (Contact CoHort Software, Berkeley, CA, USA) (version 6.4; CoHort Software, Berkeley, CA). All data are presented as means \pm standard error. Regression analyses were used to examine relationships between DQI and plant SV parameters. All graphs were created with Sigmaplot 10.0
(Systat Software, CA) (version 10.0; Systat Software, San Jose, CA). To investigate whether morphological and physiological measurements were sensitive to SV, the coefficients of $\mathrm{R}^{2}$ between $\mathrm{SV}$ indices and DQI were examined by regression analyses. Several models were tested, with the nonlinear regression model being selected as the best interpretation of the relationship between the SV index and DQI. All models were evaluated for goodness of fit by the graphical analysis of residuals, computing $R^{2}$. The experiment was performed twice independently for a randomized design of the growth environment, sampling day, and morphological and physiological analyses.

\section{Results}

Classifications of morphological and physiological parametersfor $S V$

Among all seedling morphological attributes, RGP (when categorized in levels) was the best predictor of SV in all tested plants (Table 1). RGP values were separated into 5 groups based on the number of new roots, the average of each group ranging from 6.76 (level 1) to 46.67 (level 5). It is noteworthy that level 5 displayed a seven-fold increase over level 1. In step with RGP values, the remaining parameters were also separated into five levels and tested for significance among levels in each parameter. Among 6 morphological and 7 physiological parameters, the trends and rates of increases from level 1 to 5 in DQI, LAI, total dry mass, $\triangle F / F m$ ', and $q P$ were similar to the RGP index. For example, group 5 had a significantly higher DQI level (3.47) compared to the other four groups, ranging from 1.31 (level 4) to 0.23 (level 1). LAI values increased significantly from levels $1(1.50)$ to 5 (4.30). Moreover, the $\triangle \mathrm{F} / \mathrm{Fm}$ ' ratio from level $5(0.11)$ exhibited significantly higher ChlF than levels $4(0.10)$ to $1(0.06)$. However, SQ values of seedlings increased from levels 1 (7.35) to 2 (7.84) and then dropped to 3.13 at level 5. S:R ratios peaked at 3.48 (level 3) and dropped significantly to 1.07 (level 5). Fo values remained high from levels 1 (373.56) to 4 (358.67) and then dropped to the lowest value (280.89) at level 5. Fm values showed a significant difference only at level 5 . Furthermore, neither NPQ nor Fv'/Fm' differed significantly among different levels. Slight decreases in NDVI levels were noted in all plants as DQI levels were extended and increased. Overall, different responses and levels among all morphological and physiological parameters existed in $P$. lanceolata during SV testing.

\section{Relationships among DQI, LAI, and $\triangle F / F m$ '}

The calibration curves of DQI and corresponding morphological and physiological parameters can reveal information on LAI and $\triangle F / F m$ ' and serve as a reference for SV of star cluster Relationships among LAI, $\triangle \mathrm{F} / \mathrm{Fm}$, and LAI $\times\left(\Delta \mathrm{F} / \mathrm{Fm}{ }^{\prime}\right)$ and $\mathrm{DQI}$ were nonlinear. Regression analysis showed that LAI, $\triangle \mathrm{F} / \mathrm{Fm}$ ', and LAI $\times\left(\Delta \mathrm{F} / \mathrm{Fm}^{\prime}\right)$ were significantly and positively correlated with $\mathrm{DQI}$ at $\mathrm{R}^{2}$ $=0.84,0.59$, and 0.93 , respectively (Fig. $1 \mathrm{~A}, \mathrm{~B}, \mathrm{C}$ ), suggesting that DQI occurred when both $L A I$ and $\triangle F / F m$ ' were better than the individual index used for SV in star cluster. The distinctive multiple indices between $\mathrm{LAI} \times(\Delta \mathrm{F}$ / Fm') and DQI clearly show that these morphological and physiological indices can be used as more-precise metrics for developing leaf SV estimation algorithms. 
Table 1. Dickson quality index (DQI) values of star cluster (Pentas lanceolata) were divided into 5 levels. The remaining morphological and physiological parameters were separated into the same five groups as the DQI index

\begin{tabular}{|c|c|c|c|c|c|}
\hline \multirow[b]{2}{*}{ Morphological index } & \multicolumn{5}{|c|}{ Level of quality } \\
\hline & $\mathrm{L} 1$ & $\mathrm{~L} 2$ & L3 & $\mathrm{L} 4$ & $\mathrm{~L} 5$ \\
\hline DQI & $0.23 \pm 0.006 \mathrm{e}$ & $0.34 \pm 0.019 \mathrm{~d}$ & $0.76 \pm 0.039 \mathrm{c}$ & $1.31 \pm 0.092 \mathrm{~b}$ & $3.47 \pm 0.310 \mathrm{a}$ \\
\hline RGP & $6.76 \pm 1.667 \mathrm{e}$ & $15.23 \pm 2.410 \mathrm{~d}$ & $24.48 \pm 3.009 c$ & $35.33 \pm 4.410 \mathrm{~b}$ & $46.67 \pm 3.333 \mathrm{a}$ \\
\hline LAI & $1.50 \pm 0.279 c$ & $1.85 \pm 0.090 \mathrm{bc}$ & $2.55 \pm 0.530 \mathrm{bc}$ & $3.00 \pm 0.476 b$ & $4.30 \pm 0.387 \mathrm{a}$ \\
\hline Total dry mass $(\mathrm{mg})^{y}$ & $2.50 \pm 0.156 \mathrm{c}$ & $3.65 \pm 0.042 c$ & $7.55 \pm 1.591 \mathrm{bc}$ & $9.20 \pm 2.576 \mathrm{ab}$ & $14.14 \pm 1.984 \mathrm{a}$ \\
\hline SQ & $7.35 \pm 0.982 \mathrm{ab}$ & $7.84 \pm 1.124 \mathrm{a}$ & $6.38 \pm 0.135 \mathrm{ab}$ & $4.79 \pm 1.182 \mathrm{bc}$ & $3.13 \pm 0.547 c$ \\
\hline S:R ratio & $2.63 \pm 0.541 \mathrm{ab}$ & $2.52 \pm 0.654 \mathrm{ab}$ & $3.48 \pm 0.489 a$ & $2.06 \pm 0.498 \mathrm{ab}$ & $1.07 \pm 0.331 \mathrm{~b}$ \\
\hline Physiological index & $\mathrm{L} 1$ & $\mathrm{~L} 2$ & $\mathrm{~L} 3$ & $\mathrm{~L} 4$ & $\mathrm{~L} 5$ \\
\hline$\Delta \mathrm{F} / \mathrm{Fm}$ & $0.06 \pm 0.037 \mathrm{~d}$ & $0.07 \pm 0.002 \mathrm{~cd}$ & $0.08 \pm 0.005 \mathrm{c}$ & $0.09 \pm 0.004 \mathrm{~b}$ & $0.11 \pm 0.003 \mathrm{a}$ \\
\hline Fo & $373.56 \pm 2.475 \mathrm{a}$ & $344.89 \pm 5.300 \mathrm{~b}$ & $349.67 \pm 6.083 b$ & $358.67 \pm 7.669 \mathrm{ab}$ & $280.89 \pm 6.447 \mathrm{c}$ \\
\hline $\mathrm{Fm}$ & $1555.11 \pm 68.850 \mathrm{a}$ & $1426.78 \pm 4.390 \mathrm{a}$ & $1507.11 \pm 63.82 \mathrm{a}$ & $1466.67 \pm 82.99 \mathrm{a}$ & $1234.67 \pm 40.82 b$ \\
\hline NPQ & $2.22 \pm 0.120 \mathrm{a}$ & $2.17 \pm 0.113 \mathrm{a}$ & $1.88 \pm 0.176 \mathrm{a}$ & $1.87 \pm 0.095 \mathrm{a}$ & $2.26 \pm 0.121 \mathrm{a}$ \\
\hline $\mathrm{Fv}^{\prime} / \mathrm{Fm}^{\prime}$ & $0.50 \pm 0.006 \mathrm{a}$ & $0.50 \pm 0.013 \mathrm{a}$ & $0.53 \pm 0.010 \mathrm{a}$ & $0.52 \pm 0.022 \mathrm{a}$ & $0.51 \pm 0.010 \mathrm{a}$ \\
\hline $\mathrm{qP}$ & $0.13 \pm 0.007 \mathrm{c}$ & $0.14 \pm 0.007 \mathrm{bc}$ & $0.14 \pm 0.006 \mathrm{c}$ & $0.16 \pm 0.009 b$ & $0.21 \pm 0.004 \mathrm{a}$ \\
\hline NDVI & $0.80 \pm 0.005 \mathrm{a}$ & $0.83 \pm 0.009 \mathrm{a}$ & $0.82 \pm 0.026 \mathrm{a}$ & $0.80 \pm 0.005 \mathrm{a}$ & $0.75 \pm 0.011 \mathrm{~b}$ \\
\hline
\end{tabular}

Values are means \pm standard error $(\mathrm{n}=4)$. Within the same index, different lowercase letters among levels are significantly different at $p \leq 0.05$ by Fisher's LSD test.

$\mathrm{DQI}$ - Dickson quality index; LAI - leaf area index; $S Q$ - sturdiness quotient; $S: R$ - shoot/root; $\triangle F / F m$ ' - effective quantum yield; Fm - maximal fluorescence yield of the dark adapted state; NPQ - nonphotochemical quenching coefficient; Fv'/Fm' - maximum quantum yield; qP - photochemical quenching coefficient; NDVI normalized difference vegetation index.

\section{Discussion}

Plant quality is a challenging parameter to characterize. Measurements of plant quality can be classified into three categories of plant attributes: morphological, physiological, and performance (Ritchie et al., 2010). Some of these are not regularly measured, and performance attributes such as time to flowering after transplanting can be time-, labor-, and space-intensive. Therefore, the identification of relatively simple, precise, and nondestructive measurements to characterize quality attributes using morphological and physiological measurements that are correlated to subsequent growth is needed. Furthermore, during the selection of methods and interpretation of SV testing, the assessment of performance should be clearly separated from the assessment of field survival. Root growth potential (RGP) refers to the ability of seedlings to develop new roots and grow under favorable conditions, and is frequently used as an index for SV (Stone, 1955). A large RGP value represents vigorous roots that are capable of absorbing water and nutrients for subsequent growth, resulting in a higher survival rate and superior seedling vigor that serves as an indicator of plant survivability and adaptability after transplanting (Tsakaldimi et al., 2009). Root growth index is a quantitative expression of RGP, therefore, we carefully removed the roots from each plant's attached soil medium without damaging them at $90 \mathrm{~d}$, and found that the number of new roots averaged 6.76 to 46.67 (level 1 to 5, respectively) (Tanaka et al., 1997).

DQI incorporates three parameters (seedling dry mass, sturdiness quotient, and $S: R$ ratio) and serves as a useful indicator for quality, and is often used during seedling selection. A larger DQI value indicates a more desirable phenotype, and the greater the value of DQI, the better the SV, indicating robustness and balance in the distribution of biomass in the seedling (Scalon et al.,
2014). A smaller plant height/root collar diameter ratio indicates a sturdy plant of better quality. In addition, a small $S: R$ ratio reveals a heavy dry mass for roots and is an indication of superior quality. DQI can also serve as a predictor for soil fertility, and poor SV may be due to limited root growth or poor soil fertility (Thompson, 1985). In our study, DQI values at levels 3 to 5 suggests it is an acceptable SV for star cluster based on our observations that some leaves looked epinastic and senescent at levels 1 and 2, but most leaves of the same plants appeared healthier and greener throughout the duration of the experiment at levels 3 to 5 (photos not shown). Thus, the general trend observed for all tested plants is that larger seedlings had better DQI values. The poor performance of smaller seedlings may be due to their relatively small RGP, leading to insufficient water uptake. DQI provides an objective rating of young plant quality by integrating morphological parameters that contribute to the perceived quality of seedlings and roots.

Measurements for plant biomass such as total dry mass are often used as indicators for seedling survival. Total dry mass is representative of the net gain of photosynthesis, and plants with higher total dry mass $s$ have better growth potential and are of better quality (Manas et al., 2009). The accumulation of dry matter in seedlings is mainly controlled by the source and sink of photosynthesis and will have a direct impact on plant appearance; i.e., by having more leaves or higher biomass. In this study, although total seedling dry mass reflects SV and is significantly and highly correlated to DQI $\left(\mathrm{R}^{2}=0.86\right.$, data not shown), this measurement requires the destruction of test samples and is not suitable for star cluster SV testing. Other than total seedling dry mass, plant height and root diameter are often used to assess SV. Tall and slender seedlings have lower survival rates after transplanting (Jacobs et al., 2005). Root diameter during the nursery period can help predict future growth quality after transplanting and provides information 

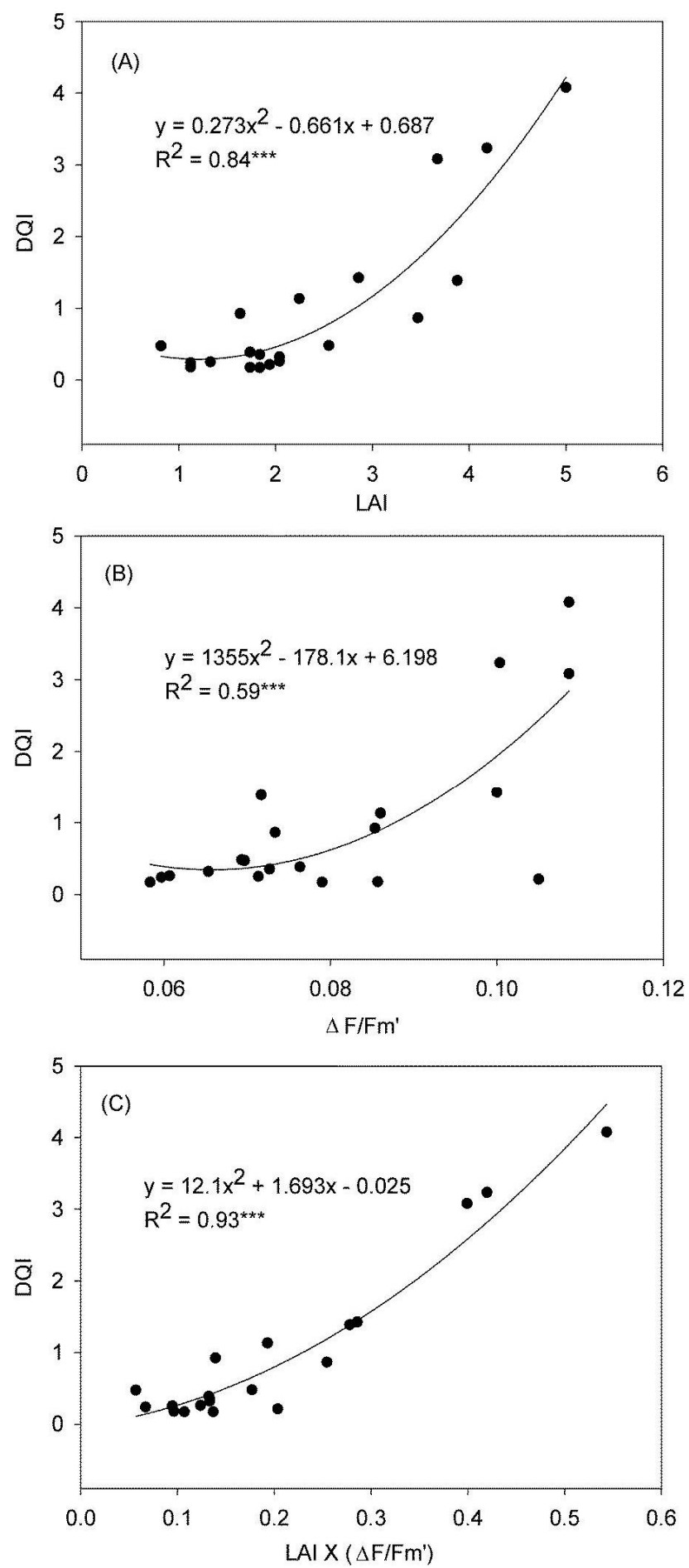

Fig. 1. Relationships between DQI and LAI (A), $\Delta \mathrm{F} / \mathrm{Fm}$ ' (B), and LAI $\times\left(\Delta \mathrm{F} / \mathrm{Fm}^{\prime}\right)(\mathrm{C})$ of star cluster (Pentas lanceolata) seedlings at $90 \mathrm{~d}$. Each symbol represents one plant, and 4 plants were randomly selected from each level of quality. ${ }^{* * *}$ Significant at $p \leq 0.001$. DQI - Dickson quality index; LAI - leaf area index; $\triangle \mathrm{F} / \mathrm{Fm}$ ' - effective quantum yield

on whether seedlings are solid and sturdy or lean and weak (Davis and Jacobs, 2005). This parameter represents the ability of the seedling to resist and withstand physiological damage and is often used as a SV index of the potential for growth and survival of container-grown seedlings (Wilson and Jacobs, 2006). The sturdiness quotient (SQ) can be used to evaluate seedling survival rate and growth performance. Large SQ ratios are often found in densely planted seedlings, which usually grow tall and slender. Roller (1976) discovered that black spruce seedling SQ values $>6$ reflected more intolerance to strong wind, drought, and frost, resulting in substantial losses compared to seedlings with lower SQ values. In this study, seedlings with thick roots included many lateral and fibrous roots, and SQ was calculated as the seedling height divided by root collar diameter. Although the $\mathrm{R}^{2}$ value between SQ and DQI of star cluster was $0.69(p<0.001$, data not shown), this index is not suggested for seedling vigor tests due to mainly timeconsuming. The $S: R$ ratio represents the dry mass ratio of shoot and root, and is an important determinant of seedling survival. Seedlings with very large $S: R$ ratios indicate disproportionately large shoot biomass relative to roots, resulting in a disparity in water distribution and inferior quality. Alternatively, a very small $S: R$ ratio suggests insufficient shoot growth. The $S: R$ ratio varies according to plant type and age, but similar species often have comparable S:R ratios. Generally, older plants have larger $\mathrm{S}: \mathrm{R}$ ratios while younger plants have smaller ratios (Thompson, 1985). When assessing seedling vigor of deciduous hardwoods, plants with higher quality possessed small S:R, and S:R and DQI were correlated and used as an index for quality (Wilson and Jacobs, 2006). Our study shows a significant and positive correlation $\left(\mathrm{R}^{2}=0.33\right.$, data not shown) between DQI and $S: R$ in star cluster, and is not an ideal index for SV assessment due to its weak correlation value.

Leaves are the primary interface for the exchange of energy and matter between terrestrial ecosystems and the atmosphere. The most common measure of leaf quantity is leaf area index (LAI). LAI is defined as one half of the total leaf surface area divided by the ground area. LAI has been used as a land surface biophysical parameter and is a required input parameter for almost all models simulating ecosystem processes (Song, 2012). Turner et al. (1999) compared spectral vegetation indices with different radiometric correction levels across three temperate zones and found that normalized difference vegetation index (NDVI) based on surface reflectance best correlates with LAI. However, the NDVI-LAI relationship reaches an asymptote when LAI is $>3$. They also found that NDVI $x$ LAI differed between conifers and other types of trees. In our study, the NDVI-LAI relationship was weak $\left(\mathrm{R}^{2}=0.45\right.$, $p<0.001$, data not shown). Unlike NDVI and other indices, when DQI and LAI were applied to the full set of data, there was a strongly significant correlation $\left(\mathrm{R}^{2}=0.84, p\right.$ $<0.001$ ) between DQI and LAI (Fig.1A), showing that LAI is an accurate and nondestructive predictor of leaf SV in star cluster. Reflectance indices might be useful for measuring SV in star cluster when developing indices for nondestructive chlorophyll estimation. NDVI is used to assess chlorophyll content and can indicate photosynthetic capacity. Reflectance spectra can be affected by plant photochromes, water content, biochemical conponents, and tissue configuration (Zou et al., 2011). Photosynthetic capacity directly determines the amount of biomass; therefore, the photosynthetic response to a plant's 
174

environment can be considered the surviving factor for plants growing in various environments (Dillen et al., 2012). Carter (1998) reported that the efficiency of photosynthesis and stomatal conductance was increased when the NDVI value of pine canopies was $>0.7$. In this study, the lower NDVI of leaves in level 5 (0.75) compared to level $1(0.8)$ indicated that fewer leaves in level 1 had lower chlorophyll concentrations, which is consistent with visual observations (photos not shown). Unfortunately, NDVI was not strongly correlated to DQI $\left(\mathrm{R}^{2}=0.41, p<\right.$ 0.001 , data not shown).

Routes for light energy absorbed by Chl molecules in photosynthetic tissue are used to drive photosynthetic processes, dissipate heat, and re-emit light energy (i.e., ChlF) (Maxwell and Johnson, 2000). Measuring the yield of ChlF gives specific information about photochemical efficiency and heat dissipation. ChIF components can be used to measure different functional levels of photosynthesis, and changes in ChlF also can quickly assess plant physiological responses during stress (Laing et al., 2000). $\triangle \mathrm{F} / \mathrm{Fm}$ ' shows the actual photochemical ability of PSII under lighted conditions and has a linear relationship with the $\mathrm{CO}_{2}$ fixation rate. $\triangle F / F m^{\prime}$ is an index of photosynthetic potential as well as the potential for photochemical dissipation, and reveals the percentage of PSII that is open and its effectiveness in capturing complexes from photo energy and later transfer to quanta (Fracheboud and Leipner, 2003). $\triangle F / F m$ ' may fall due to a drop in either $q P$ or $\mathrm{Fv}^{\prime} / \mathrm{Fm}$ ', or both. When the absorbed light energy has not dissipated completely, excess energy will suppress photosynthetic system activity, causing part of the PSII reaction center to remain in a cyclic status and shut down, and lower both qp and $\triangle \mathrm{F} / \mathrm{Fm}$ ' values (Molina-Bravo et al., 2011). Yang et al. (2017) examined seasonal relationships between ChlF and photosynthesis at the ecosystem scales and explored how leaf ChlF was linked with canopy-scale solar-induced ChlF in a temperate deciduous forest, suggesting that ChlF can be a powerful tool to track photosynthetic rates at leaf, canopy, and ecosystem scales. In addition, Liu et al. (2018) also reported that both solarinduced ChlF and reflectance-based vegetation indices (ie., NDVI) in winter wheat under different irrigation treatments positively and significantly correlated with root zone soil moisture for measuring vegetation variation even when the LAI or chlorophyll content was at high levels. The combined analysis of ChlF and specific leaf area help to explore the photosynthetic responses of tree species to forest tree diversity that can individuate the most suitable species composition and the structure of stands to minimize the impacts of stressful environments and climate change on forests (Pollastrini et al., 2017). In this study, seedlings with higher DQI, RGP, and LAI also had higher values of $\triangle F / F m$ ' and $q P$. The reason for the increase in $\triangle F / F m$ ' may be the increase in $\mathrm{qP}$, and excess energy in PSII would be increased leading to lower Fo and Fm values. Alternatively, Fo and Fm values in level 1 declined to a larger degree than level 5 , which may be due to greater photoinhibition when plants were suffering from fewer leaves and roots. Lesser numbers of leaves and roots increased the likelihood of photoinhibition, characterized by a decline in leaf ChlF, and photoinhibition generally occurred more rapidly than in plants with more leaves. The functions of the thylakoid membrane in Chl sensitively respond to various morphological parameters and directly or indirectly affect the functioning of PSII; thus, lower ChlF values might be obtained on a plant with lesser leaves. Having fewer leaves destabilizes the PSII light system, resulting in a separation between light harvesting complex II and PSII reaction centers that raise Fo and Fm at different rates (Yamane et al., 1997).

A positive and significant correlation $\left(\mathrm{R}^{2}=0.59\right)$ was observed between $\triangle F / F m$ and DQI (Fig. 1B), demonstrating the applicability of the ChlF index for measuring DQI and also suggesting that $\triangle F / F m$ ' can replace DQI for a nondestructive estimation of SV in star cluster. However, weak or nonsignificant correlations were detected between other ChlF variables and DQI (data not shown). Although Fo, Fm, Fv'/Fm', NPQ, and $\mathrm{qP}$ parameters are related through photochemical quenching, they were less sensitive to $D Q I$ than $\triangle F / F m$ '. The average time required to measure Fm', Fm, and Fo from a pre-darkadapted sample was only $1 \mathrm{~s}$. This means that many hundreds of individual plants may be screened per day, providing ample opportunity for the discovery of individuals that manifest quality indicators and exhibit greater seedling vigor. Not only can simple evaluations of photosynthesis be made, but also the relationships among photosynthetic efficiency, heat dissipation, and fluorescence can be assessed. It is expected that the new index can be comprehensively used to estimate which plant contain DQI and RGP with high $\mathrm{R}^{2}$. A strong and significant correlation $\left(\mathrm{R}^{2}=0.93, p<0.001\right)$ was found between LAI $\times(\Delta \mathrm{F} / \mathrm{Fm})$ and DQI (Fig. 1C). These potential discrepancies justify measuring both parameters simultaneously, and regression models using multiple variables performed much better than those using a single predictive variable. LAI $\times$ $\left.(\Delta \mathrm{F} / \mathrm{Fm})^{\prime}\right)$ was predicted using duplex data from validation datasets, predictions were compared to actually measured DQI and RGP values of star cluster, and SV indices were predicted.

\section{Conclusions}

This study provides evidence that morphological and physiological levels can improve SV in star cluster in a screen house. The newly developed regression models for evaluating SV are linked to nondestructive measurements of large-scale seedling vigor in bedded ornamental plants grown in an open field. However, these data still reflect the morphological and physiological attributes that contribute to our perception of crop quality and subsequent growth in outdoor planting sites (Currey et al., 2012). Additional opportunities exist to modify DQI to include a broader suite of traits of interest (e.g., branch and/or node numbers) to floriculture crop producers or emphasize important traits. Furthermore, variables could be weighted with coefficients to emphasize or deemphasize traits based on relevance. The formula for LAI $\times\left(\Delta \mathrm{F} / \mathrm{Fm}{ }^{\prime}\right)$, as used in our research, can be used as a starting point and could be modified to include or weight other variables of interest. Currently, we are using these values to select for photosynthetic capacity in plants for stress tolerance. 


\section{Acknowledgements}

This work was financially supported by the National Taiwan University from Excellence Research Program Core Consortiums under the project of "Sustainable approach of water resources - Development and application of sponge city and bionic system technologies" (NTUCCP107L891308) within the framework of the Higher Education Sprout Project by the Ministry of Education (MOE) and "Bridging water, energy and food nexus: Developing methodologies, risk management systems, substantive solutions and decision tools" (107-2627-M002-015) by Ministry of Science and Technology (MOST) in Taiwan.

\section{References}

CarterGA (1998). Reflectance wavebands and indices for remote estimation of photosynthesis and stomatal conductance in pine canopies. Remote Sensing of Environment 63:61-72.

Chiu YC, Hsu WC, Chang YC (2015). Detecting cabbage seedling diseases by using chlorophyll fluorescence. Engineering in Agriculture, Environment and Food Food 8:95-100.

Currey CJ, Hutchinson VA, Lopez RG (2012). Growth, morphology, and quality of rooted cuttings of several herbaceous annual bedding plants are influenced by photosynthetic daily light integral during root development. HortScience 47:25-30.

Davis AS, Jacobs DF (2005). Quantifying root system quality of nursery seedlings and relationship to outplanting performance. New Forests 30:295-311.

Demmig-Adams B, Adams WW, Barker DH, Logan BA, Bowlong DR, Verhoeven AS (1996). Using chlorophyll fluorescence to assess the fraction of absorbed light allocated to thermal dissipation of excess excitation. Physiologia Plantarum 98:253-264.

Devitt DA, Morris RL, Fenstermaker LK (2005). Foliar damage, spectral reflectance, and tissue ion concentrations of trees sprinkle irrigated with waters of similar salinity but different chemical composition. HortScience 40:819-826.

Dickson A, Leaf AL, Hosner JF (1960). Quality appraisal of white spruce and white pine seedling stock in nurseries. The Forestry Chronicle 36:10-13.

Dillen SY, Beeck MO, Hufkens K (2012). Seasonal patterns of foliar reflectance in relation to photosynthetic capacity and color index in two co-occurring tree species, Quercus rubra and Betula papyrifera. Agricultural and Forest Meteorology 160:60-68.

Ellison DS, Schutzki R, Pascal N, Cregg B (2016). Root growth potential, water relations and carbohydrate status of ash alternative species following pre-plant storage. Urban Forestry \& Urban Greening 18:5964.

Facchi A, Baroni G, Boschetti M, Gandolfi C (2010). Comparing optical and direct methods for leaf area index determination in a maize crop. Journal of Agricultural Engineering 41:33-40.

Fracheboud Y, Leipner J (2003). The application of chlorophyll fluorescence to study light, temperature, and drought stress. In: DeEll JR, Toivonen PM (Eds). Practical Applications of Chlorophyll Fluorescence in Plant Biology,Kluwer,Dordrecht pp 125-150.
Huang C, Zhao S, Wang L, Anjum S, Chen M, Zou C (2013). Alteration in chlorophyll fluorescence, lipid peroxidation and antioxidant enzymes activities in hybrid ramie (Boehmeria nivea L.) under drought stress. Australian Journal ofCropScience 7:594599.

Jacobs DF, Salifu KF, Seifert JR (2005). Relative contribution of initial root and shoot morphology in predicting field performance of hardwood seedlings. New Forests 30:235-251.

Kitao M, Lei TT, Koike T, Tobita H, Maruyama Y (2006). Tradeoff between shade adaptation and mitigation of photoinhibition in leaves of Quercus mongolica and Acer mono acclimated to deep shade. Tree Physiology 26:441-448.

Kowalczyk K, Sieczko L, Goltsev V, Kalaji HM, Gajc-WolskaJ, GajewskiM, ... Cetner MD (2018). Relationship between chlorophyll fluorescence parameters and quality of the fresh and stored lettuce (Lactuca sativa L.). ScientiaHorticulturae 235:70-77.

Laing W, Greer D, Sun O, Beets P, Lowe A, Payn T (2000). Physiological impacts of magnesium $(\mathrm{Mg})$ deficiency in Pinus radiata: Growth and photosynthesis. The New Phytologist 146:47-57.

Levizou E, Drilias P, Psaras GK, Maneta Y (2005). Nondestructive assessment of leaf chemistry and physiology through spectral reflectance measurements may be misleading when changes in trichome density cooccur. New Phytologist 165:463-472.

Liu L, Yang X, Zhou H, Liu S, Zhou L, Li X, Yang J, Wu J (2018). Relationship of root zone soil moisture with solar-induced chlorophyll fluorescence and vegetation indices in winter wheat: A comparative study based on continuous ground-measurements. Ecological Indicators 90:9-17.

Manas P, Castro E, Heras J (2009). Quality of maritime pine (Pinus pinaster Ait.) seedlings using waste materials as nursery growing media. New Forests 37:295-311.

Mattsson A (1997). Predicting field performance using seedling quality assessment. New Forests 13:227-252.

Maxwell K, Johnson GN (2000). Chlorophyll fluorescence-a practical guide. Journal of Experimental Botany 51:659-668.

Molina BR, Arellano C, Sosinski BR, Fernandez GE (2011). A protocol to assess heat tolerance in a segregating population of raspberry using chlorophyll fluorescence. Scientia Horticulturae 130:524530.

Pollastrini M, Nogales A, Benavides R, Bonal D, Finer L, Radoglou K, Bussotti F (2017). Tree diversity affects chlorophyll a fluorescence and other leaf traits of tree species in a boreal forest. Tree Physiology 37:199208.

Porcar CA, Pfündel E, Korhonen JF, Juurola E (2008). A new monitoring PAM fluorometer (MONI-PAM) to study the short- and long-term acclimation of photosystem II in field conditions. Photosynthesis Research 96:173-179.

Radoglou K, Raftoyannis Y (2002). The impact of storage, desiccation and planting date on seedling quality and survival of woody plant species. Forestry75:179-190.

Raymond FK, Roger NC (1999). Spectroscopic determination of leaf biochemistry using band depth analysis of absorption features and stepwise multiple linear regression. Remote Sensing of Environment 67:267-287.

Ritchie GA, Landis TD, Dumroese RK, Haase DL (2010). Assessing plant quality. In: Landis TD, Dumroese RK, Haase DL (Eds). The container 
176

tree nursery manual. United States Department of Agriculture, Washington DC pp 17-82.

Roller KJ (1976). Field performance of container-grown Norway and black spruce seedlings. Canadian Forestry Service Department of the Environment. Information Report M-X-64.17p.

Scalon SP, Jeromini TS, Mussury RM, Dresch DM (2014). Photosynthetic metabolism and quality of Eugenia pyriformis Cambess. seedlings on substrate function and water levels. Anais da Academia Brasileira de Ciências 324:103-113.

Song C (2012). Optical remote sensing of forest leaf area index and biomass. Progress in Physical Geography 37:98-113.

Stone EC (1955). Poor survival and the physiological condition of planting stock. Forest Science 1:90-94.

Strachan IB, Pattey E, Boisvert JB (2002). Impact of nitrogen and environmental conditions on corn as detected by hyperspectral reflectance. RemoteSensing of Environment 80:213-224.

Tanaka Y, Brotherton P, Hostetter S, Chapman D, Dyce S, Belanger J, Johnson B, Duke S (1997). The operational planting stock quality testing program at Weyerhaeuser.New Forests 13:423-437.

Thompson BE (1985). Seedling morphological evaluation: what you can tell by looking. In: Duryea ML (Ed). Evaluating seedling quality: principles, procedures, and predictive abilities of major tests. Proceedings of the workshop of Forest Research Laboratory of the Oregon State University, Oregon pp 59-71.

Tsakaldimi M, Tsitsoni T, Ganatsas G, Zagas T (2009). A comparison of root architecture and shoot morphology between natural regenerated and container seedlings of Quercusilex L. Plant and Soil 324:103-113.

Turner DP, Cohen WB, Kennedy RE (1999). Relationships between leaf area index and Landsat TM spectral vegetation indices across three temperate zone sites. RemoteSensing of Environment 70:52-68.
Vidaver WE, Lister GR, Brooke RC, Binder WD (1991). A manual for the use of variable chlorophyll fluorescence in the assessment of the ecophysiology of conifer seedlings. In FRDA forest resource development report 163, British Columbia, Canada.

Wightman KE (1999). Good tree nursery practices: practical guidelines for community nurseries. International Centre for Research in Agroforestry, Nairobi, Kenya.

Wilson BC, Jacobs DF (2006). Quality assessment of temperate and deciduoushardwood seedlings. New Forests 31:417 433.

Wilson B, Jacobs DF (2012). Chlorophyll fluorescence of stem cambial tissue reflects dormancy development in Juglans nigra seedlings. New Forests 43:771-778.

Wu CW,Lin KH, Lee MC, Peng YL, Chou TY, Chang YS (2015). Using chlorophyll fluorescence and vegetation indices to predict the timing of nitrogen demand in Pentas lanceolata. Korean Journal of Horticultural Science and Technology 33:845-853.

Yang H, Yang X, Zhang, Heskel M, Sun S, Tang J (2017). Chlorophyll fluorescence tracks seasonal variations of photosynthesis from leaf to canopy in a temperate forest. Global Change Biology 23:2874-2886.

Yamane Y, Kashino Y, Koike H, Satoh K (1997). Increases in the fluorescence $\mathrm{F}_{0}$ level and reversible inhibition of Photosystem II reaction center by high-temperature treatments in higher plants. Photosynthesis Research 52:57-64.

Zou X, Shi J, Hao L, Zhao J (2011). In vivo noninvasive detection of chlorophyll distribution in cucumber (Cucumis sativus) leaves by indices based on hyperspectral imaging. Analytica Chimica Acta 706:105-112. 